\title{
RENITÊNCIAS DA IMAGEM ${ }^{1}$
}

\author{
Rosângela Miranda Cherem \\ Jefferson W.Kielwagen
}

RESUMO: O presente artigo apresenta uma série de imagens pertencentes ao arsenal da História da Arte, problematizando algumas complexidades que envolvem sua abordagem. Em contraposição aos procedimentos de generalização e homogeneização, considera-se a composição serial como possibilidade para pensar a repetição que surge como diferença, bem como o recurso de montagem como operação que conjuga diversas temporalidades. Também está contemplada tanto uma reflexão sobre o ornamento como um modo de remeter aos efeitos tácteis e ultrapassar a mera representação visual, como o empilhamento enquanto tentativa para preencher o que ultrapassa a obra e encobre o vazio e o informe. O fragmento, enfim, é considerado como desintegração e re-configuração de mundo.

PALAVRAS-CHAVE: História da Arte; imagem; anacronismo; ornamento.

\section{1 - História da Arte como operação de montagem}

É propósito deste artigo problematizar as obras de arte para além do ato de colher evidências e seguir pegadas destinadas apenas a compreender um contexto cultural, religioso, político e assim por diante. Na contradança da cronologia, as obras são pensadas como portadoras de impurezas e descontinuidades temporais, sendo que para alcançá-las é preciso recorrer aos procedimentos de montagem, construindo séries capazes de reconhecer a sobrevivência de certas inquietações e perturbações - que ficaram ali contidas e que aparecem pelos efeitos de cintilação, em ocasiões de proximidade empática. Recusando um mero encadeamento temporal, busca-se um território capaz de tangenciar novas complexidades e articulações, considerando a produção artística menos através de um varal cronológico-evolutivo e mais através de questões que envolvem diferentes sensibilidades e percepções sobre a imagem, realizando uma espécie de dobra temporal que conjuga diferença-semelhança, proximidade-distância, imobilidade-aceleração.

A este respeito, Didi-Huberman observa que a obra de arte é sempre portadora de algo já visto que volta subterraneamente como fantasma, atravessando e mesclando diferentes

\footnotetext{
${ }^{1}$ Artigo produzido para apresentação no XVIII Seminário de Iniciação Científica da UDESC, do Programa de Pós-Graduaçãoem Artes Visuais da UDESC, em 2008.
} 
temporalidades pelos arremessos fragmentários da memória. Suspensa entre dois começos, a imagem se refere tanto àquilo que se faz bloco de afecções e sensações num dado momento, como é trazido por forças pretéritas que não cessam de retornar, seja como sobrevivência póstuma ou como potência associada ao rebatimento do passado no presente, conferindo à imagem um caráter de espectralidade ${ }^{2}$.

Por sua vez, refletindo sobre o fato de que a falência da representação no pensamento moderno faz com que todas as identidades sejam simuladas e produzidas como efeito ótico sob o jogo da diferença e repetição, Deleuze ${ }^{3}$ destaca que a diferença se constitui como algo que não está subordinado ao idêntico e que, não sendo sua negação, oposição ou contradição, relaciona-se ao pensamento nietzscheano - uma vez que se coloca como vibração secreta, desvio ou transgressão de uma potência singular que ocorre entre generalidades. Impedindo que um termo seja traduzido por outro e que o particular seja reposto conforme leis com permanências e variáveis, a repetição é desvio e lapso, sendo que o repetível nada mais é do que uma singularidade insubstituível que retorna como potência e permite inventar gravitações e saltos para agir em função daquilo que não se é e nem se tem.

Dito de outro modo, as imagens trazem consigo diferentes temporalidades. E se por um lado, os procedimentos de montagem também remetem a certos diálogos benjaminianos relativos ao inconsciente ótico, igualmente podem se relacionar à concepção foucaultiana de arquivo em sua condição de exceção e desvio, descontinuidade e falta, cujas sombras e silêncios nada têm de neutro ou ingênuo. Considerando as imagens através de uma espécie de constelação que só existe pelos efeitos de condensação e desvio ou como acoplamento de diferentes temporalidades, postula-se a sobrevivência das formas menos pelo que foi herdado e mais pelos desdobramentos e possibilidades resultantes, sendo as mesmas consideradas pelos incessantes procedimentos de recombinação.

Abordando o nascimento de um vasto e diverso arsenal imagético a partir da reprodutibilidade técnica, André Malraux ${ }^{4}$ ressalta as complexas metamorfoses no que diz respeito aos usos e sentidos da obra de arte. Para ele, se o que conhecemos como obra de arte foi definido a partir do nascimento do museu, esta nos chega fora de seu contexto e sua única função é a de ser uma obra de arte. Se o museu amplia a capacidade de destacar, ressuscitar ou apagar obras, transpondo-as de seu ambiente exclusivamente religioso ou da corte para o teatro mundano, o meio da reprodutibilidade impressa e fotográfica possibilita a cada um que o acessa uma expansão praticamente infinita de sua imaginação, permitindo que possa constituir seu próprio acervo ou museu imaginário. Se o museu trouxe a pintura com a intenção de produzir admiração pela beleza, a

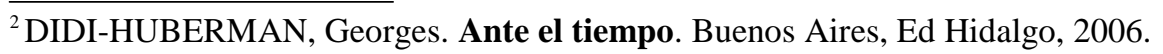

${ }^{3}$ DELEUZE, Gilles. Diferença e Repetição. S.P.: Ed. Graal, 1988, p. 21 e seg.

${ }^{4}$ MALRAUX, André. O museu imaginário. Lisboa/ São Paulo,Ed. 70, 2000, cap.IV. 
reprodutibilidade técnica fez com que fossem criadas novas comparações, agrupamentos e classificações, explorando novas combinações e ângulos, valorizando fragmentos, isolando e recombinando detalhes, metamorfoseando o objeto e proporcionando novas conexões no repertório visual.

Ainda que a história da arte tenha tornado-se a história do fotografável, ocorrendo alterações de tamanhos e cores ou simplificações de texturas e relevos, assim como os baixosrelevos, estátuas e arquitetura perderam sua profundidade e tornaram-se pranchas, é preciso lembrar que o museu imaginário torna-se de todos, sendo formado pelas recordações particulares de cada um e independendo de um local específico para existir. Acrescentando novas iluminações às imagens, a obra reativa sua potência e se coloca em constante movimento, num processo de leitura infinito Assim, a reprodução não rivaliza com a obra, mas evoca-a, fazendo com que sobreviva menos o pelo que foi dito sobre ela e mais pelo que ainda nos diz.

\section{2 - História da Arte como caleidoscópio}

Interrogando os regimes de verdade que sustentam a História da Arte como disciplina, Aby Warburg e Walter Benjamin comparecem como interlocutores favoráveis ao recurso da montagem, indo na contra-mão dos manuais que simplificam a relação vida e obra, tomam a obra de arte como expressão ou reduzem as obras a estilos e escolas. Daí decorre a problematização da imagem em sua relação com o tempo, interrompendo o fluxo regular das coisas e tornando-se uma

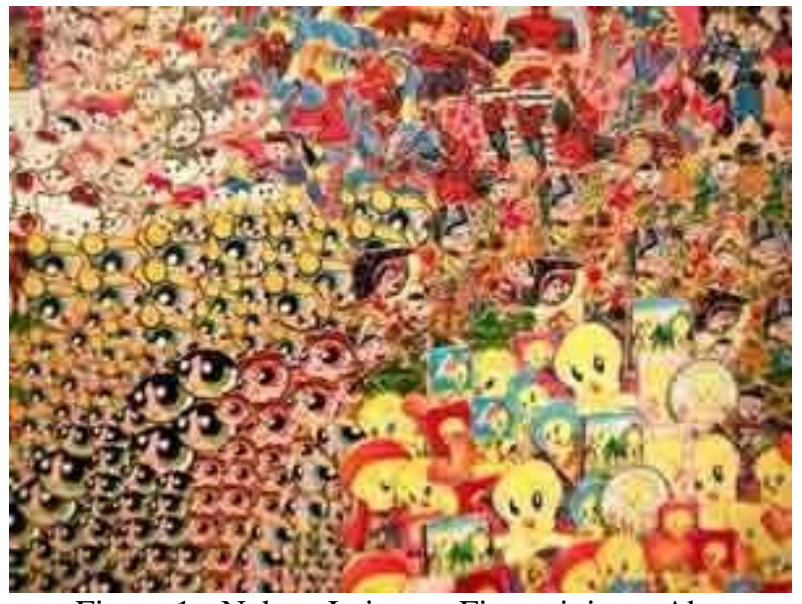

Figura 1 - Nelson Leirner - Figurativismo Abstrato, 2004. Stickers sobre madeira, 67" x 86.5". espécie de lei avariada e subterrânea.

Antes de avançar, convém ainda recorrer à perspectiva do historiador da arte DidiHuberman $^{5}$, para quem Walter Benjamin não apenas tinha conhecimento do caleidoscópio, inventado em 1817 por Alphonse Giroux, como também recorreu a ele como um modelo teórico para abordar as variedades e combinações da modernidade. Assim como, no tubo de imagem

${ }^{5}$ DIDI-HUBERMAN, Georges. Ante el tiempo. Buenos Aires, Ed Hidalgo, 2006, Cap. II. 
polido, ficam guardados pedaços desfiados de tecido, pequenas conchas, plumas, poeiras e cacos de vidro, a passagem do século XIX ao XX pode ser lida pela moda, pelos panoramas, pela fotografia, pelas exposições, pelo ambiente privado, reclames, cinema, e daí em diante. O paradigma dos novos tempos não poderia mais ser dado pela materialidade irrepetível da pintura, repleta de simbologias partilhadas através de um repertório erudito e inscrita numa longa tradição referenciada pela noção de beleza, juízo estético, gosto e estilo.

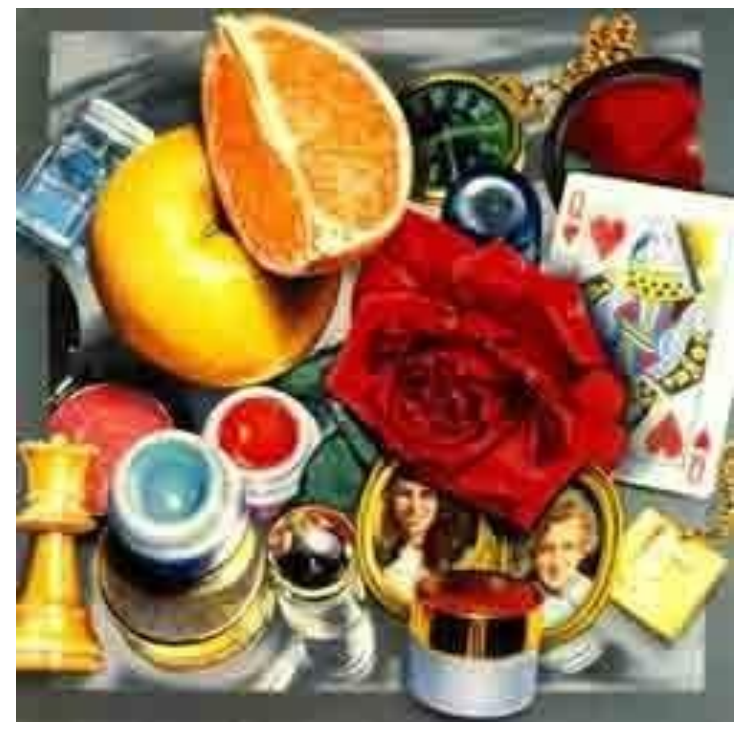

Figura 2 - Audrey Flack - Queen, 1976 (80 x 80“)

Dispensando a memória e a experiência em prol das vivências, o caleidoscópio tem por princípio o movimento constante e o reembaralhamento infinito das formas, cujas semelhanças são mantidas por um processo de reprodutibilidade, sendo assimiladas com sentidos semelhantes aos das novidades pelas crianças, ou seja, sem vínculos de temporalidade contínua com o passado. $\mathrm{O}$ que emerge são formas iridescentes através do elevado poder de configuração dos detritos e da cintilância dos resíduos. Através de um movimento incessante, que produz tanto sobressaltos e quedas de formas como choques e recomposições, a imagem surge como re-configuração ou re-montagem visual, que é testemunhada num tempo de perturbações e turbulências, variações e alterações.

As idéias de fragmento e caleidoscópio pode ser sugeridas em relação com Figurativismo Abstrato, de Nelson Leirner (Figura 1). No movimento errático das dessimetrias multiplicadas, a estrutura inesgotável da imagem é dada pelo caráter ilusório da novidade e pela constante desmontagem interior das coisas, conjugada com elementos díspares. Recorrendo a pilhagem e ao empilhamento intempestivo, o mesmo pode ser dito da natureza- morta de Audrey Flack (Figura 2), observando na presença aparentemente aleatória de objetos cotidianos e ordinários um jogo que apenas encena o fortuito das formas, cores e texturas. Nesta operação o que sobrevive é a presença das naturezas-mortas, amplamente difundidas na Europa setentrional setecentista como modo de falar do humano na sua ausência, problematizando o efêmero e a perecibilidade da matéria, bem como pelas problemáticas modernistas interessadas em tematizar a banalidade como modo de interrogar a arte e suas possibilidades.

Considerando a história em des-tempo e extemporaneidade, ou seja, como anacronismo, Benjamin esboçou não apenas um modelo ótico, mas um novo modo de conceber a História da 
Arte, voltando-se para a leitura da catástrofe insidiosa do mundo, sendo o passado um arsenal de escombros e fragmentos constantemente re-configurados. É assim que, recusando a retenção temporal, a transformação progressiva e historicista, além das tramas hierarquizadas com pretensões à objetividade, os acontecimentos e as imagens foram pensados por ele como procedimentos de recombinação e montagem. Trata-se de considerar a sobrevivência das formas menos como o que foi herdado e mais pelos desdobramentos e possibilidades resultantes. Ainda que o caleidoscópio arrisque-se num dado momento a cair e partir como um objeto deixado na mão da criança, sua variedade iridescente interroga a estrutura do tempo. 


\section{3 - A obra de arte como encenação da matéria}

Uma senhora está recostada em sua cama, num quarto vitoriano (Figura 3). Na estante convivem o jogo de chá e o rechonchudo Buda Hotei - santo japonês das guloseimas e testemunha impassível do teatro da matéria, a grande ilusão. Cortina e vestido se desdobram e derramam sobre a composição, enquanto motivos florais preenchem a parede e o biombo, à direita. Para a cabeceira da cama, listras, e no primeiro plano, objetos prosaicos: criado-mudo, banquinho, um punhado de

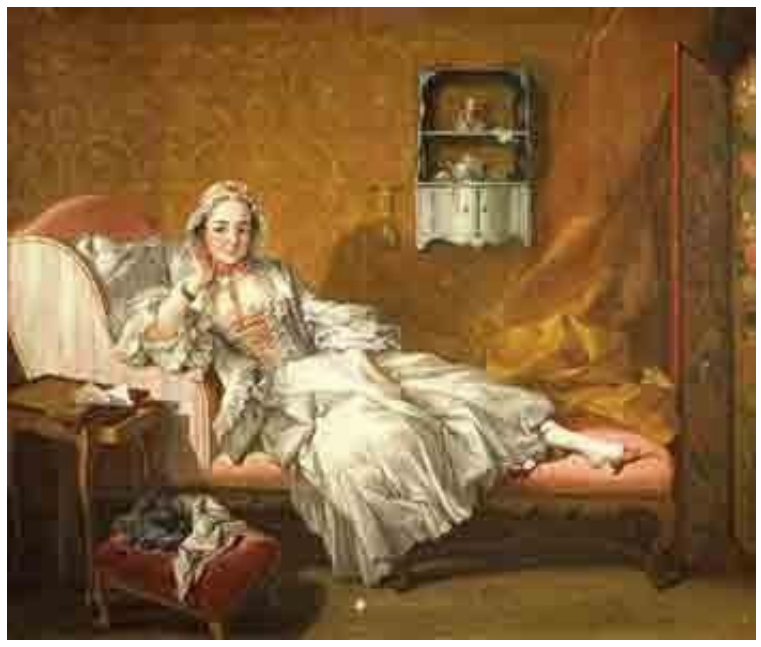

Figura 3 - Boucher, Uma Senhora em Sua Cama, 1743, óleo s/ tela, 57x68 cm, Coleção Frick, N.Y. panos amarrotados, um diário e uma carta. Não há zonas neutras nessa imagem, em que tudo parece levar a uma dispersão do olhar: guloseimas ornamentais.

Com o que se parecem essas superfícies quase palpáveis criadas por Boucher? Com nada, a não ser com elas mesmas: jogos de linhas e figuras que não querem reapresentar o mundo, mas pensar ludicamente sua representação - construindo um campo de cores e texturas, estampas e revestimentos inverossímeis - tornando assim a vida natural suspeita e mostrando que o esplendor não passa de um truque, sendo a ilusão a mais sutil das realidades. 


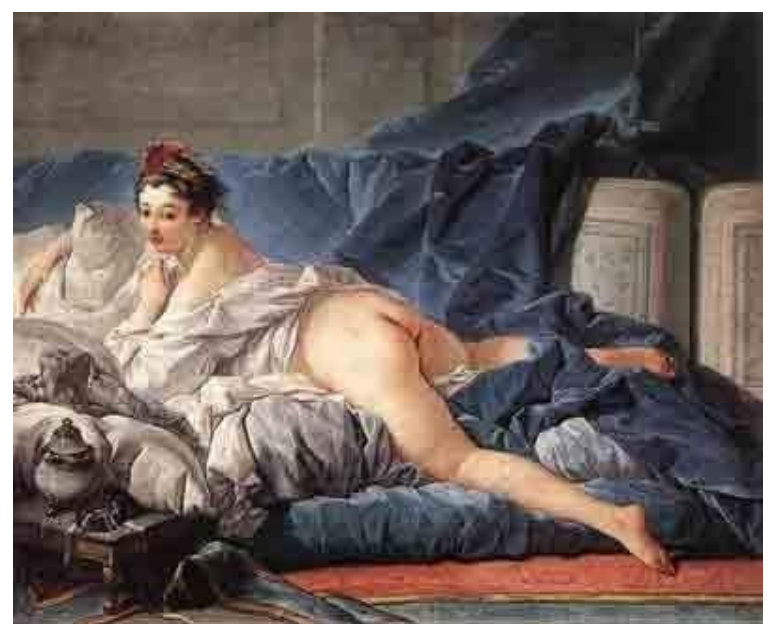

Figura 4 - Boucher, Odalisca Morena, 1745. Óleo s/ tela, Museu do Louvre.

Uma odalisca morena, parcialmente nua, repousa sobre colchões e cobertores (Figura 4). As dobras de sua carne luminosa se destacam sobre as dobras azuis dos lençóis, prevalecendo na composição uma profusão de superfícies ornamentadas: um baixo-relevo na parede, ao fundo; arabescos por trás dos cobertores, e motivos vegetais no tapete. Em meio à tumultuada complexidade da cena, a nudez parece brilhar, convidando o olhar a uma espécie de toque. Entre as dobras do tecido e as da carne Boucher estabelece um diálogo, tornado possível pelo fato de que estas figuras impõem uma inseparabilidade do claro e do escuro: no apagamento dos contornos, o claro não pára de mergulhar no escuro.

Abordando o barroco como função operatória, Deleuze ${ }^{6}$ observa as dobras que se desdobram ao infinito, considerando a questão a partir de Leibniz, filósofo que desenvolveu a noção de mônada como uma casa, em cujo andar inferior caberiam os organismos e amontoados viventes, enquanto no andar de cima caberia a alma, caracterizada como o próprio espaço sem janelas e alheio à exterioridade. Todavia, reconhecendo a divisão infinita e as porções contaminadas e circunvizinhas, observou a textura porosa que operava nestes espaços, recusando a mera compartimentalização em proveito de labirintos de continuidades, cuja menor unidade é a própria dobra em incessante movimento.

Assim, diferentemente do quadro como modelo exterior e em conformidade com a perspectiva renascentista da janela, esta noção relaciona-se ao regime de luzes e cores, cuja claridade relativa e figuras sem contorno remetem a um fundo comum e a uma natureza obscura. Reafirmando a matéria como expressão de uma vastidão sempre exterior e uma profundidade infinita, assinala a virtualidade incessante do teatro das matérias, destacando no acúmulo das espessuras um mundo que não possui existência fora delas, e que se multiplica de modo cada vez mais distanciado do centro.

\footnotetext{
${ }^{6}$ DELEUZE, Gilles. A dobra. Leibniz e o barroco. S.P.: Papirus, 2005.
} 
Em sua biblioteca ou escritório, a Marquesa de Pompadour posa para um retrato (Figura 5). Aqui também, a pele nua parece brilhar entre dobras; a exuberância do vestido verdeesmeralda, adornado com rosas, fitas e rendas, soma-se à obscuridade geral da imagem. Boucher reveste todas as superfícies com motivos predominantemente vegetais, sendo que os ornamentos desaparecem, ao fundo, na escuridão completa. Por trás da Marquesa, na penumbra, pode-se distinguir uma estante de madeira, também ricamente adornada, sobre a qual repousam um anjinho barroco e um relógio, indômitos, persistem como sombras: Eros, e

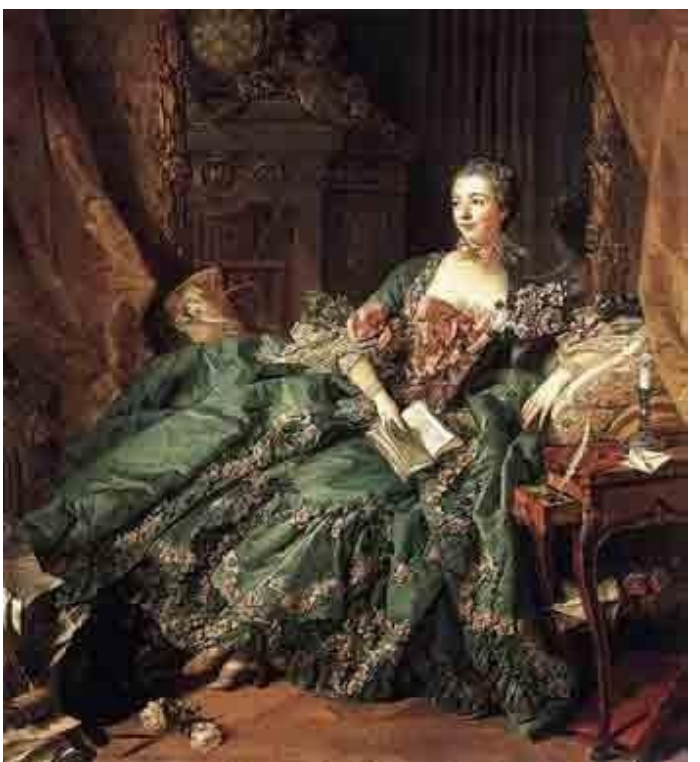

Figura 5 - Boucher, Retrato da Marquesa de Pompadour, 1756. Óleo s/ tela Alte Pinakothek, Munique.

Cronos - que em última instância, também é

Thanatos.

Se perceber é perceber nas dobras, desdobrar é sobredobrar; em sua condição drapeada, o pensamento, como a mônada, impõe um mundo infinito como contraponto ao modelo ótico. À geometria da percepção curvilínea corresponde a uma arquitetura da visão para um momento de crise: antes de o mundo perder seus princípios, o esplêndido momento em que alguma coisa se mantém em vez do nada, em que responde à miséria do mundo com o excesso de princípios. ${ }^{7}$

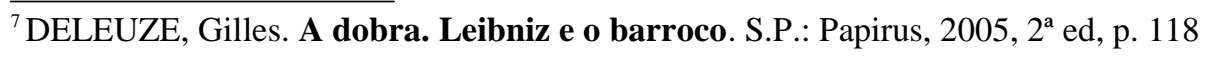




\section{4 - A obra de arte como presença do informe}

Dentre as obras de arte que marcam a influência barroca no Brasil - deixada pelos missionários católicos desde o século XVII encontram-se alguns dos mais pungentes e desmedidos exemplos de ornamentação. Este parece ser o caso do Retábulo da Basílica de Nossa Senhora do Carmo, em Recife (Figura 6). Sob o predomínio do dourado, abundam as formas e cores mais variadas numa riqueza de detalhes que, indo além da dispersão, beiram a opressão. Como surgem estas superfícies? O que elas guardam ou a qual vazio podemos suspeitar que encobrem? Até onde é possível compreender seu preciosismo ornamental e por que insistem em

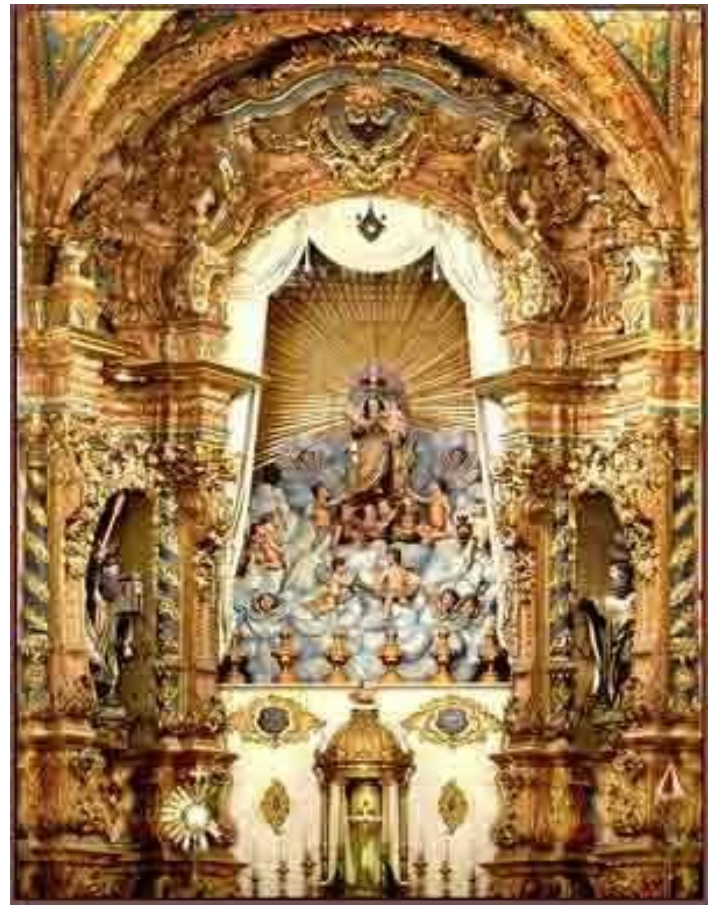

Figura 6 - Retábulo da Basílica de Nossa Senhora do Carmo, em Recife. reafirmar o dispêndio?

Considerando as dobras barrocas e o ornamento como formas de atração pelo abandono e dispêndio, reconhecemos os retábulos em suas diversas camadas acolhidas pela memória e sedimentadas em meio aos empilhamentos do tempo. Pode-se pensá-los como guardiões da passagem entre os mundos medieval e moderno, que tanto em sua forma como em seu conteúdo, parecem conter as tensões provenientes desta trajetória, respondendo de modo diferente a uma problemática do espaço.

Em meio ao frenesi decorativo ou às referências teatrais e escultóricas, pode-se

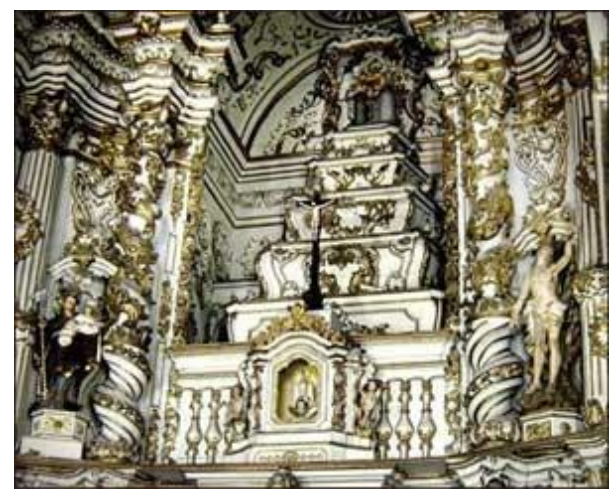

Figura 7 - Matriz de Santo Antônio, Recife. freqüentemente reconhecer tanto as minúcias arquitetônicas e figurações divinas quanto os reinos vegetal, mineral, humano e animal - sem ignorar o fato de que estas obras quase sempre estão divididas em inúmeras partes, oferecendo-se como janelas que remetem ao sagrado. Já no primeiro plano, elementos como rochas ou vegetação, colunas ou ruínas, detalhes de ourivesaria ou cortinado assinalam uma espécie de cenografia, que se deslinda como oferenda de cores $e$

formas. 
Prosseguindo na reflexão sobre o fundo que sempre se coloca fazendo o olhar perfurar a superfície, retornemos aos retábulos como elo - entre uma antiga tradição de afrescos em paredes e catacumbas e um olhar moderno, que tudo prescruta, percorrendo desde os detalhes reveladores da quintessência e do supralunar até a infinita variedade dos domínios sublunares ${ }^{8}$. Portadoras de uma exatidão que atinge aquele que para elas se volta, as imagens dos retábulos desfazem a evidência do mundo através do recurso de uma mutação que embaralha os sentidos, especialmente produzindo uma confusão do código visual, onde a centralidade retiniana é substituída pela realidade táctil, desdobrando um jogo de casualidade que se afirma pelos objetos e seres que servem para fazer pensar a existência, através dos vestígios por ela deixados e que a elas remetem.

Questão que, ao mesmo tempo, funda e solapa o fenômeno do olhar, emoldurando ou preenchendo o vazio dos corpos e cenas, as imagens ali contidas parecem dirigir-se intimamente a quem para elas se volta, ao mesmo tempo em que remetem ao vazio, ao exterior e ao indefinido, fundo sórdido sobre o qual ela continua afirmando as coisas em seu desaparecimento. ${ }^{9}$ Assim, o que elas preenchem refere-se a uma ausência indeterminada da forma, ou seja, a uma sorte de humanização do informe, retirando a obscuridade do destino em sua essência, que é a de ser sombra.

\footnotetext{
${ }^{8}$ DIDI-HUBERMAN,George. Devant l'image. Paris: Lês Editions de Minuit. 1990, capítulo IV.
}

${ }^{9}$ BLANCHOT, Maurice. O espaço literário. R.J.: Ed. Rocco, 1987, p.256 


\section{5 - A obra de arte como fragmento inquietante}

Observemos uma última série de imagens, onde a presença de um corpo é quase revelada para em seguida desaparecer, deixando enfeitiçado o olhar de quem se perde pelos detalhes. Esse definitivamente não é um retrato comum (figura 8): peito e testa são abóboras, e o nariz é uma pêra enquanto uvas e espigas compõem a cabeleira; amendoins são bigodes, vagens são sobrancelhas, e as maçãs do rosto são... maçãs? No pescoço o gogó é uma batata e dos ombros de repolho pende uma faixa de flores. Do que seria a orelha direita pende um figo maduro, e da esquerda um par de azeitonas. O curioso rosto parece sorrir, como se zombasse de quem o observa, interrogando se o que surge é um rosto ou uma coleção de objetos. O que as coisas ali contempladas pretendem abarcar? Qual a

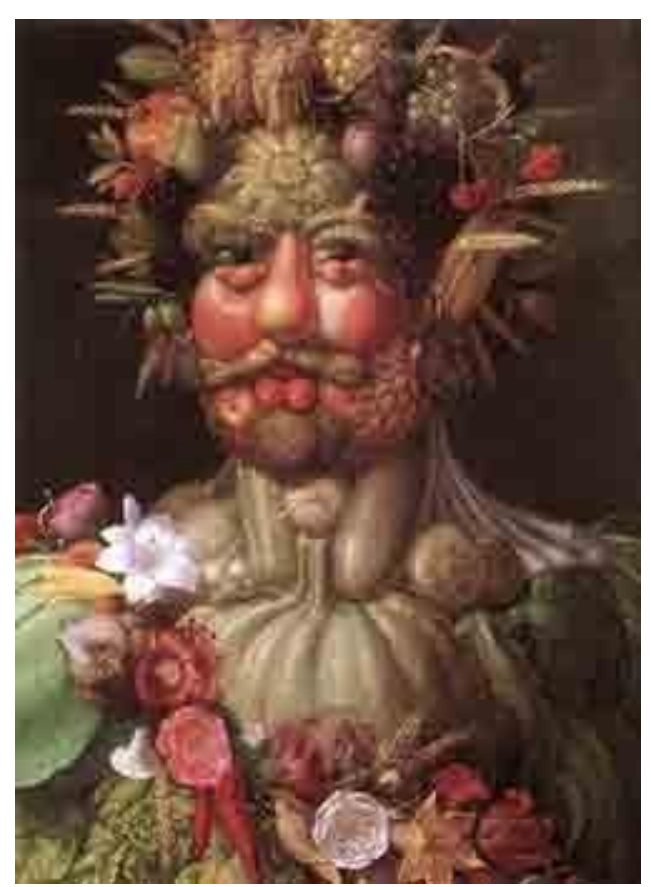

Figura 8 - Giuseppe Arcimboldo. Vertumnus, 1590-1591. Óleo sobre madeira, Skoklosters Slott, Balsta, Suécia. origem destes estranhos fragmentos, e a que outro fragmento - ou integridade - remetem?

Questões semelhantes são colocadas pela obras do escultor italiano Alberto Giacometti que, distanciando-se dos conceitos idealistas e humanistas, na passagem dos anos 20-30 buscou um modo de pensar o mundo tribal e as fontes primitivas para além das considerações meramente formais. Assinalando o desejo de mutilar o suporte, aproximou-se dos conceitos de altus e sacer, presentes também na noção de alto-baixo, sagrado-profano e violação-criação. Desdobrada como alteração e ambivalência, tal compreensão tanto interessava a Freud como permitia aproximações com as noções batailleanas de informe e acéfalo. Em sua leitura surrealista bastante singular, particularmente através de composições horizontais, tal como Cabeça-Paisagem, o escultor dilacera o corpo, enfatizando a baixeza e a desorientação, ao mesmo tempo em que o sacrifício e a destruição se reapresentam como instância da criação ${ }^{10}$. Desse modo, o artista pôde pensar a relação da arte moderna com o cadáver e também considerar a cabeça como máscara em processo de decomposição.

\footnotetext{
${ }^{10}$ KRAUSS, Rosalind. La originalidad de lavanguarda y otros mitos modernos. Madrid: Aliana Ed, 1985, p. 64 a 98
} 


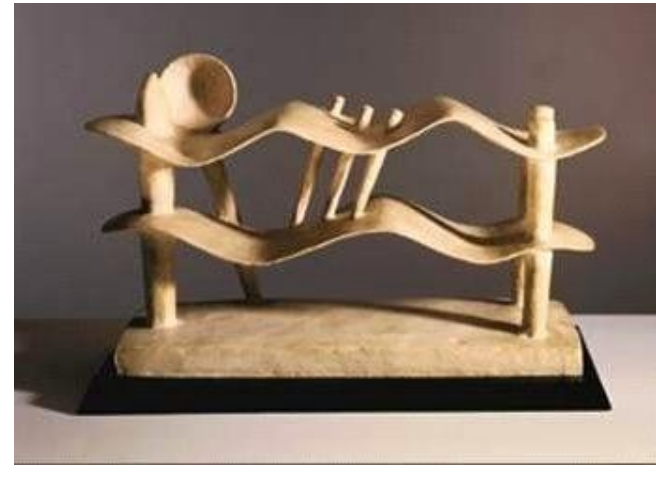

ALBERTO GIACOMETTI Giacometti, Femme couchée qui rêve, 1929

Figura 8
Ainda na mesma década, Roger Caillois escreveu sobre o perturbador fenômeno da psicastenia. Abordando a homocromia como o fenômeno em que a imagem retiniana é transposta para a pele através da ação automática produzida pela excitação luminosa nas células cromóforas, o que por sua vez resulta na produção de similitude de certos animais com o outro e com o meio, procurou pensar sobre esta circunstância também conhecida como telefotografia recusando-se a simplificá-la, quer pela explicação

finalista da religião, quer pelo mecanicismo científico. Uma vez que restos de animais mimetizados podem ser encontrados nas vísceras de predadores, tal fenômeno deveria ser considerado menos como uma defesa para fins de preservação e mais como um instinto de abandono, posto que o olho do animal pode ser pensado como um veículo de fascinação, que ultrapassa as soluções dadas tanto pelo acaso como pela adaptação. Ainda que sofisticada, a imitação não deixaria de ser uma armadilha, e a distinção do organismo em relação ao meio estaria comprometida por um distúrbio da percepção espacial que poderia ser sintetizado pela afirmação sei onde estou, mas não me sinto no lugar onde me encontro. ${ }^{I l}$ Nesta tendência à imobilidade e ao inorgânico o que se confirma é uma economia de dispêndio, verificando-se o mesmo no conhecimento e na arte - cujos movimentos mais atraentes acabam por agir como força final, resultando numa espécie de uniformidade ou anulação que conduz ao inanimado.

Desse modo, enquanto para Giacometti a escultura moderna nasce da desintegração do corpo, uma vez que a arte possui um vínculo sacrificial com práticas ancestrais, para Caillois em sua atração inescapável pelo meio e o outro, o olho como dispositivo de sobrevivência se transforma em fatal armadilha. Assim, em ambos os raciocínios, elaborados em tempos de entreguerras, pode-se reconhecer um território de investigações que colocam em xeque os conhecimentos fundados na certeza retiniana e nos preceitos da razão como instrumento de progresso e emancipação. Não à toa, neste mesmo período emerge o conceito de beleza convulsa, relacionado à idéia de realidade configurada, tornando aleatório o espaço divisório no interior da imagem.

\footnotetext{
${ }^{11}$ CAILLOIS, Roger. Mimetismo e psicastenia legendária. Revista Che Voui, ano 1, $\mathrm{n}^{\mathrm{o}}$, Cooperativa Cultural Jacques Lacan, Porto Alegre: 1986.
} 